\title{
Quantifying the increasing use of anti-vascular endothelial growth factor therapy in ophthalmology
}

\author{
Jonathan A. Micieli*, Andrew Micieli
}

\begin{abstract}
Introduction: Bevacizumab (Avastin; Genetech Inc., South San Francisco, CA) and ranibizumab (Lucentis, Genetech Inc.) are two anti-Vascular Endothelial Growth Factor (VEGF) agents used in increasing amounts off-label to treat ocular conditions. To date, no study has quantified how far reaching these therapies have been in treating eye disease and compared their off-label use to the number of clinical trials performed. Method: A systematic search of Ovid MEDLINE using the keywords bevacizumab and ranibizumab limited to "Case Reports" was used as an index of the number of diseases treated. Each keyword was also limited to "Clinical Trials, All" and "Phase III Clinical Trials" to discern the quality of evidence for these uses.Results: Bevacizumab has been utilized for the treatment of 58 different ocular conditions, but only 14 conditions were studied in a trial, and none were part of a phase III clinical trial. Ranibizumab has been used for 17 different eye conditions, with only 6 studied in a trial and only 1 disease, "wet" age-related macular degeneration reported in 4 phase III trials. In the case reports, there were 21 different adverse events ascribed to bevacizumab and 2 to ranibizumab with retinal pigment epithelial tears being the most common. Conclusion: Bevacizumab is one of the most far reaching drugs in ophthalmology and even medicine, but it is not yet supported by high quality evidence. The much higher cost of ranibizumab may be responsible for bevacizumab's popularity among eye specialists. Patients should be fully informed about the off-label use of bevacizumab and the associated risks with its use.
\end{abstract}

KEYWORDS: anti-angiogenic therapy, bevacizumab, ranibizumab, ophthalmology

\section{INTRODUCTION}

The revolutionary concept of interfering with the growth of new blood vessels to prevent disease progression began in the field of cancer therapy (1). It was hypothesized that the growth of tumor cells could be significantly diminished if the tumour expression of pro-angiogenic proteins like Vascular Endothelial Growth Factor (VEGF) could be inhibited (2). Bevacizumab (Avastin, Genentech

*To whom correspondence should be addressed: Jonathan A. Micieli

235 Rue Sherbrooke Ouest \#207

Montreal, QC, H2X 1X8

jonathan.micieli@mail.mcgill.ca
Inc, South San Francisco, California, USA), which is a full-length monoclonal antibody directed against all biologically active forms of VEGF-A, was the first anti-angiogenic drug approved by the US Food and Drug Administration (FDA) for the treatment of metastatic colorectal cancer in conjunction with standard chemotherapy (3). In addition to the treatment of cancer, however, antiangiogenic therapy has rapidly invaded the field of ophthalmology, particularly in the diseases of the retina, where neovascularization that is spatially and temporally correlated with VEGF expression is a common theme (4). Instead of administering 
these agents intravenously where patients are susceptible to potentially deleterious side effects like hypertension and thromboembolic events (5), the current standard procedure in ophthalmology is an injection directly into the vitreous humor; this has the advantage of localizing the drug to the eye and minimizing any systemic effects (6).

The two most commonly used anti-VEGF drugs in ophthalmology are bevacizumab and the anti-VEGF-A antibody Fab fragment ranibizumab (Lucentis, Genentech Inc, South San Francisco, California, USA), although pegaptanib sodium (Macugen, OCl Pharmaceuticals, Melville, NY), a ribonucleic acid aptamer that binds and inhibits VEGF, is also available (7). Unlike bevacizumab, intravitreal ranibizumab and pegaptanib sodium have been tested in Phase III randomized controlled trials and therefore approved for the treatment of neovascular ("wet") age-related macular degeneration (AMD) (8), which is the leading cause of irreversible blindness in people over 50 in the developed world (9-11). However, the superior results of ranibizumab compared to pegaptanib sodium in the aforementioned trials have limited the use of the latter in the clinics (12). Compared to bevacizumab, the theoretical advantage of using the smaller ranibizumab fragment is that one can achieve better penetration of all layers of the retina and more effectively target VEGF since this fragment has been engineered to have a higher VEGF affinity (13). However, the relative cost of ranibizumab ( $\$ 2000$ per dose) versus the much cheaper bevacizumab ( $\$ 50$ per dose) has made the latter drug the one of choice for treating other eye diseases off-label when VEGF is implicated, especially when government or insurance coverage is not available (14).

A quick perusal of the ophthalmology literature undoubtedly reveals a plethora of studies utilizing bevacizumab and ranibizumab off-label to treat diseases of the cornea and iris, in addition to those of the retina. For the great majority of the conditions, no randomized controlled trials have been performed to provide high-quality evidence for utilizing these agents, and therefore, many patients are subject to a number of unknown potential risks when receiving these drugs. To date, no study has systematically quantified how far reaching bevacizumab and ranibizumab have been in the field ophthalmology and compared the off-label use to that supported by high quality evidence. The goal of the current study is to quantify how many ocular disease bevacizumab and ranibizumab have been used for, as represented by published case reports, and to compare this to the number of clinical trials that have been performed. In addition, the number of adverse events reported in case reports will be quantified and discussed in terms of VEGF's critical physiological role in the body.

\section{METHODS}

As an index for how far reaching bevacizumab and ranibizumab have been in treating eye diseases, the number of published case reports, clinical trials and phase III clinical trials indexed by Ovid MEDLINE (1996 to August week 1 2009) were utilized. The search strategy, involved using the term bevacizumab or ranibizumab as a keyword. A search result is obtained if the keyword is found in the original title, abstract, name of substance word, or subject heading word. For each keyword, the search results were limited in three different ways: the first involved limiting the results to "Case Reports" which are defined by MEDLINE as "clinical presentations that may be followed by evaluative studies that eventually lead to a diagnosis" (15). The two other search limitations involved limiting each keyword to "Clinical Trials, All" and "Phase III clinical trials".

According to MEDLINE, a "clinical trial" is defined as "work that is the report of a pre-planned clinical study of the safety, efficacy, or optimum dosage schedule of one or more diagnostic, therapeutic, or prophylactic drugs, devices, or techniques in humans selected according to predetermined criteria of eligibility and observed for predefined evidence of favorable and unfavorable effects," and a "Phase III clinical trial" is "work that is a report of a pre-planned, usually controlled, clinical study of the safety and efficacy of diagnostic, therapeutic, or prophylactic drugs, devices, or techniques after phase II trials.

A large enough group of patients is studied and closely monitored by physicians for adverse response to long-term exposure, over a period of about three years in either the United States or a foreign country" (15). All search strategies were limited to the English language. 


\section{RESULTS}

The results of the search strategies utilizing either bevacizumab or ranibizumab as keywords are presented in Figure 1. Compared to those for ranibizumab, the reports published with a keyword of bevacizumab were more numerous in the category of case reports (385 vs. 39 ), all clinical trials (239 vs. 30 ) and phase III clinical trials (28 vs. 8). From the 385 case reports published for bevacizumab, 229 (59\%) described the efficacy, an adverse event, or the characteristics of the drug alone or in combination therapy for an eye condition. Of the remaining 156 papers, 151 were on a topic that did not involve the treatment of the eye such as cancer therapy and 5 were excluded from search since they were retrospective reviews or reports that did not contain sufficient information to discern which eye conditions was treated with bevacizumab. As demonstrated in Table 1, a total 58 different ocular conditions were treated with bevacizumab in the 229 case reports, the most commonly reported condition being wet AMD.

Upon further analysis of the 239 publications classified as a clinical trial for bevacizumab, only 14 different eye conditions represented by 88 publications were studied, the most frequent also being wet AMD (Table 1). There were a total of 144 clinical trial publications on a topic outside the scope of ophthalmology and 7 papers were excluded since they either studied adverse events or other features of bevacizumab treatment for the eye without the mention of the particular conditions being treated.
Finally, none of the publications classified as a Phase III Clinical Trial for bevacizumab were on a topic in ophthalmology, as summarized below in Table 1. Consequently, all of the conditions treated were considered off-label.

There were 39 case reports retrieved from the search using ranibizumab as a keyword. From these case reports there were a total of 17 different eye conditions treated with ranibizumab alone or in combination, represented by 36 publications. There was one report that was excluded since it reported the incidence of endophalmitis in an office setting due to anti-VEGF therapy in general. From the publications classified as clinical trials, there were only 6 different eye diseases studied with neovascular AMD being the most numerous. Moreover, wet AMD was the only condition where there existed Phase III Clinical Trials, which have subsequently led to its approval for the treatment of this disease (Table 2). The 4 trials, which have been described in 8 publications from the MEDLINE search, include the ANCHOR [AntiVEGF Antibody for the Treatment of Predominantly Classic Choroidal Neovascularization in AMD; (16)], MARINA [Minimally Classic/Occult Trial of the Anti-VEGF Antibody Ranibizumab in the Treatment of Neovascular AMD; (17)], FOCUS [(RhuFab V2 Ocular Treatment Combining the Use of Visudyne to Evaluate Safety; (18)] and PIER [Efficacy and Safety of Ranibizumab in Subjects with Subfoveal Choroidal Neovascularization with or without Classic CNV Secondary to AMD; (19)] studies.

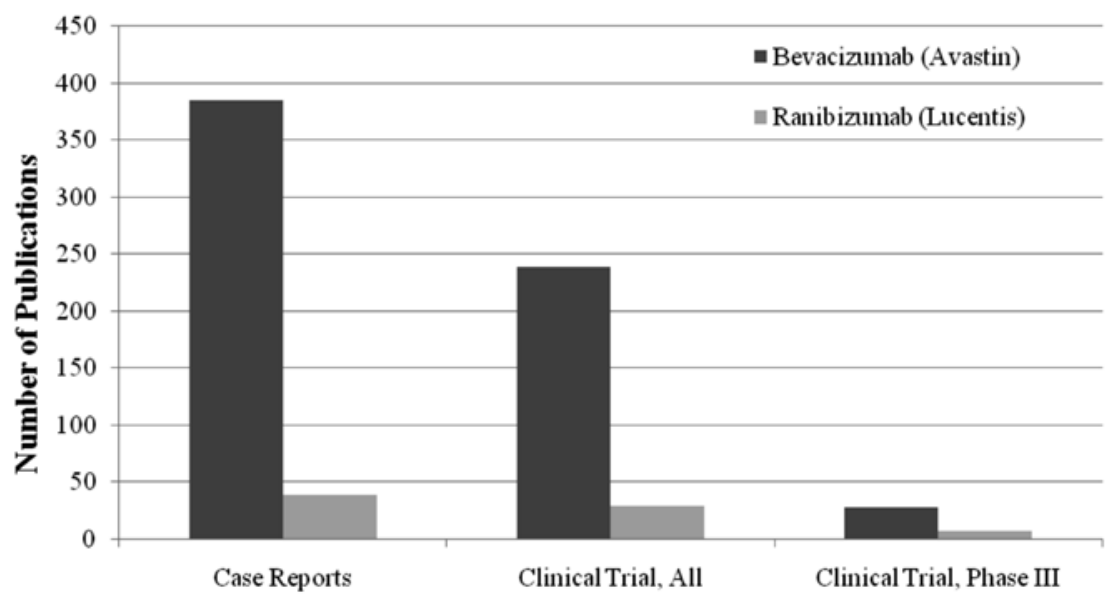

Figure 1: Results of the Ovid MEDLINE search strategy utilizing the keywords bevacizumab or ranibizumab and limited to the category of case reports, all clinical trials or phase III clinical trials. 


\begin{tabular}{|c|c|c|c|c|c|c|c|c|c|}
\hline & Ocular Condition & $\begin{array}{l}\text { Case } \\
\text { Reports }\end{array}$ & $\begin{array}{l}\text { Clinical } \\
\text { Trials }\end{array}$ & $\begin{array}{c}\text { Phase } \\
\text { III } \\
\text { Trials }\end{array}$ & & Ocular Condition & $\begin{array}{l}\text { Case } \\
\text { Reports }\end{array}$ & $\begin{array}{l}\text { Clinical } \\
\text { Trials }\end{array}$ & $\begin{array}{c}\text { Phase } \\
\text { III } \\
\text { Trials }\end{array}$ \\
\hline 1 & Neovascular AMD & 51 & 32 & none & 31 & Proliferative sickle retinopathy & 2 & none & none \\
\hline 2 & NV glaucoma & 21 & 2 & none & 32 & Central serous retinopathy & 2 & none & none \\
\hline 3 & Proliferative DR & 16 & 8 & none & 33 & $\begin{array}{l}\text { Presumed ocular } \\
\text { histoplamosis (CNV) }\end{array}$ & 2 & none & none \\
\hline 4 & Corneal neovasculariation & 11 & 2 & none & 34 & ME due to occlusive vasculitis & 2 & none & none \\
\hline 5 & Angiod Streaks (CNV) & 10 & 1 & none & 35 & Punctate inner choriodopathy & 2 & none & none \\
\hline 6 & BRVO & 8 & 11 & none & 36 & Radiation Retinopathy & 1 & 2 & none \\
\hline 7 & CRVO & 8 & 7 & none & 37 & $\begin{array}{l}\text { Familial exudative } \\
\text { vitreoretinopathy }\end{array}$ & 1 & none & none \\
\hline 8 & Pathological Myopia (CNV) & 8 & 6 & none & 38 & CRAO & 1 & none & none \\
\hline 9 & ROP & 5 & none & none & 39 & Ocular ischemic syndrome & 1 & none & none \\
\hline 10 & Inflammatory CNV & 5 & 2 & none & 40 & Toxoplasmosis (CNV) & 1 & none & none \\
\hline 11 & Peripapillary CNV & 5 & none & none & 41 & $\begin{array}{l}\text { Vogt-Koyanagi Horadu } \\
\text { syndrome (CNV) }\end{array}$ & 1 & none & none \\
\hline 12 & $\begin{array}{l}\text { Retinal Angiomatous } \\
\text { Proliferation (CNV) }\end{array}$ & 5 & 1 & none & 42 & ME due to optic disc vasculitis & 1 & none & none \\
\hline 13 & Iris NV & 4 & none & none & 43 & $\begin{array}{l}\text { Post-capsule vessels } \\
\text { (after cataract surg) }\end{array}$ & 1 & none & none \\
\hline 14 & Pseudophakic cystoid ME & 4 & 2 & none & 44 & $\begin{array}{l}\text { Gronblod-Stranberg } \\
\text { syndrome }(\mathrm{CNV})\end{array}$ & 1 & none & none \\
\hline 15 & Coats disease & 4 & none & none & 45 & Vasoproliferative tumour & 1 & none & none \\
\hline 16 & Juxtafoveal telangiectasia & 4 & none & none & 46 & $\begin{array}{l}\text { PRV due to polycythemia } \\
\text { rubra vera }\end{array}$ & 1 & none & none \\
\hline 17 & Macular telangiectasia & 3 & none & none & 47 & Pterygium & 1 & none & none \\
\hline 18 & Corneal transplant & 3 & none & none & 48 & $\begin{array}{l}\text { Cystoid ME in } \\
\text { retinitis pigmentosa }\end{array}$ & 1 & none & none \\
\hline 19 & Choroidal metastases & 3 & none & none & 49 & Cystoid ME in Behcet disease & 1 & none & none \\
\hline 20 & Choroid Osteoma (CNV) & 3 & none & none & 50 & Sorsby fundus dystrophy & 1 & none & none \\
\hline 21 & Perifoveal telangiectasia & 3 & none & none & 51 & WNV choroidretinitis (CNV) & 1 & none & none \\
\hline 22 & $\begin{array}{l}\text { Polypoidal choroidal } \\
\text { vasculopathy }\end{array}$ & 3 & none & none & 52 & $\begin{array}{l}\text { Bleb hyperemia } \\
\text { (post-trabeculectomy) }\end{array}$ & 1 & none & none \\
\hline 23 & Idiopathic CNV & 2 & 1 & none & 53 & Gyrate atrophy & 1 & none & none \\
\hline 24 & Diabetic macular edema & 2 & 12 & none & 54 & $\begin{array}{l}\text { Nonarteritic Anterior Ischemic } \\
\text { Optic Neuropathy }\end{array}$ & 1 & none & none \\
\hline 25 & Multifocal choroiditis & 2 & none & none & 55 & Radiation Optic Neuropathy & 1 & none & none \\
\hline 26 & $\begin{array}{l}\text { Juxtapapillilary retinal } \\
\text { capillary hemangioma }\end{array}$ & 2 & none & none & 56 & Sponatneous cystoid ME & 1 & none & none \\
\hline 27 & Glaucoma filtering surgery & 2 & none & none & 57 & Pseudotumor cerebri (CNV) & 1 & none & none \\
\hline 28 & Eales disease & 2 & none & none & 58 & Birdshot chorioretinopathy & 1 & none & none \\
\hline 29 & $\begin{array}{l}\text { Adult-onset vitelliform } \\
\text { dystrophy }\end{array}$ & 2 & none & none & & & & & \\
\hline 30 & Best disease & 2 & none & none & & & & & \\
\hline
\end{tabular}

Table 1: The number of ocular conditions treated with bevacizumab (Avastin) indexed by the number of case reports published. $\mathrm{AMD}$ = age-related macular degeneration; $\mathrm{NV}=$ neovascular; $\mathrm{DR}=$ diabetic retinopathy; $\mathrm{CNV}=$ choroidal neovascularization; $\mathrm{BRVO}$ = branch retinal vein occlusion; CRVO = central retinal vein occlusion; ROP = retinopathy of prematurity; ME = macular edema; PRV $=$ peripheral retinal vascularization. References are provided in parentheses for those with 5 or less reports. 


\begin{tabular}{|c|l|c|c|c|}
\cline { 2 - 4 } \multicolumn{1}{c|}{ Ocular Condition } & $\begin{array}{c}\text { Case Reports } \\
\text { (references) }\end{array}$ & $\begin{array}{c}\text { All Clinical } \\
\text { Trials } \\
\text { (references) }\end{array}$ & $\begin{array}{c}\text { Phase III Trials } \\
\text { (references) }\end{array}$ \\
\hline 1 & Neovascular AMD & $\mathbf{2 0}$ & $\mathbf{2 0}$ & $\mathbf{4}$ \\
\hline 2 & Retinal Angiomatous Proliferation (CNV) & $\mathbf{2}$ & $\mathbf{1}$ & none \\
\hline 3 & CRVO & none & $\mathbf{3}$ & none \\
\hline 4 & BRVO & none & $\mathbf{1}$ & none \\
\hline 5 & Angiod Streaks (CNV) & $\mathbf{1}$ & none & none \\
\hline 6 & Diabetic macular edema & $\mathbf{1}$ & $\mathbf{1}$ & none \\
\hline 7 & Diabetic macular traction & $\mathbf{1}$ & none & none \\
\hline 8 & Idiopathic CNV & $\mathbf{1}$ & none & none \\
\hline 9 & Macular Telangiactasia & $\mathbf{1}$ & none & none \\
\hline 10 & Multifocal choroiditis & $\mathbf{1}$ & none & none \\
\hline 11 & Multiple Evanescent White Dot Syndrome & $\mathbf{1}$ & none & none \\
\hline 12 & NV Glaucoma & $\mathbf{1}$ & none & none \\
\hline 13 & Peripapillary CNV & $\mathbf{1}$ & none & none \\
\hline 14 & Pterygium & $\mathbf{1}$ & none & none \\
\hline 15 & Retinal Capillary Hemangioblastoma & $\mathbf{1}$ & none & none \\
\hline 16 & Stargardt's disease (CNV) & $\mathbf{1}$ & none & none \\
\hline 17 & Toxoplasmosis (CNV) & $\mathbf{1}$ & none & none \\
\hline 18 & Vitelliform macular dystrophy (CNV) & $\mathbf{1}$ & none & none \\
\hline 19 & Myopic CNV & & $\mathbf{1}$ & \\
\hline & & & & \\
\hline
\end{tabular}

Table 2. The number of ocular conditions that have been treated with Lucentis (Ranibizumab) and published as a case report or studied in a clinical trial. $\mathrm{AMD}=$ age-related macular degeneration; NV= neovascular; CNV = choroidal neovascularization; BRVO = branch retinal vein occlusion; CRVO = central retinal vein occlusion. References are provided in parentheses for those with 5 or less reports.

The number of adverse events published in a case report after treatment with bevacizumab totaled 20. The most frequently identified side effect was tears of the retinal pigment epithelium (RPE) in 14 papers (20), followed by endophalmitis in 6 papers (21), progression of ischemia (22) and retinal detachment (RD) with a macular hole (23) reported in 2 papers each. In addition, there was one case report describing each of the following adverse events: retinal circulatory disturbances (24), progression of a RD (25), herpetic epithelial keratitis (26), papulopustular rash (27), rebound macular edema (28), sixth nerve palsy (29), acute glaucoma (30), sustained increase in intraocular pressure (IOP) (31), visual hallucination (32), sympathetic ophthalmia following vitrectomy for endophalmitis (33), anterior uveitis (34), acute visual acuity loss (35), large subretinal hemorrhage (36), and anterior ischemic optic neuropathy (37). Perhaps the most interesting case was vitritis in the contralateral, untreated eye (38), which suggests that bevacizumab has the potential to reach the systemic circulation and penetrate many body compartments. For ranibizumab, there were 7 case reports suggesting an adverse reaction from the drug: 6 described RPE tears (39) and one described persistent ocular hypertension (40).

\section{DISCUSSION}

Despite the fact that ranibizumab is the only anti-VEGF therapy approved by licensing bodies for ocular use, bevacizumab is by far the agent with the widest scope in ophthalmology. In the current study, we identified 58 different ocular conditions that were treated off-label compared to only 19 with ranibizumab. There are a few reasons for this occurrence that include the timing of introduction of bevacizumab and ranibizumab and the relative costs of the two drugs. In mid-2005, retina specialists had two therapies that had been proven effective and safe for neovascular AMD by randomized, double masked-trials: photodynamic therapy (PDT) and pegaptanib sodium (Macugen), which is an anti-VEGF aptamer (14). Just after the results of the ranibizumab trials were being reported that same year, but before the FDA approved it for neovascular AMD in June 2006, retina specialists began using bevacizumab because it was believed 
that its similar structure to ranibizumab would confer similar results. Indeed, the American Society of Retinal Surgeons survey on bevacizumab use found that $84 \%$ of retinal specialists preferred the off-label Avastin over PDT or Macugen even though the latter drug was supported by level one scientific evidence (41). Consequently, retinal physicians began to gain confidence with the effectiveness and safety of bevacizumab despite the higher quality evidence that emerged for ranibizumab. The compounding and often important factor is the relative cost of the two drugs. Many provinces including Ontario cover ranibizumab for those with neovascular AMD over the age of 65 . However, some AMD patients, who have not yet reached the age of 65 and do not have the finances nor the insurance, are faced with a dilemma of whether to suffer the financial consequences of ranibizumab injections or receive bevacizumab which is considerable cheaper ( $\$ 2000$ vs $\$ 50$, respectively) and potentially just as effective.

The familiarity with bevacizumab has penetrated ophthalmological diseases beyond neovascularAMD and has become the most versatile agent in this area of specialization. Despite any randomized, controlled Phase III trials, bevacizumab has become included in the standard of care for many conditions including proliferative diabetic retinopathy and is administered concomitantly with laser photocoagulation at certain sessions (42). Moreover, conditions like neovascular glaucoma, which develop secondary to ischemic retinal vein occlusions or diabetic retinopathy, can be managed much more effectively with bevacizumab than with pressure lowering drops alone (43). In addition, diseases like retinopathy of prematurity, which are currently managed with destructive procedures like cryotherapy or laser photocoagulation and often accompanied by poor outcomes in aggressive cases, are being considered for treatment with bevacizumab since VEGF-induced proliferation is central to the disease process (44). However, with no large trials to adequately evaluate its safety, especially in newborns, caution must be taken as bevacizumab continues to grow in popularity. The current study did not include an analysis of pegaptanib sodium to accompany the results of bevaciumab and ranibizumab. The primary reason for this is that this more selective agent that only inhibits the $\mathrm{VEGF}_{165}$ isoform has demonstrated inferior results when compared to ranibizumab in phase III clinical trials for "wet" AMD and has consequently assumed less importance than the non-selective VEGF agents at the current time ( 7 , $12,17)$. In the future, however, pegaptanib sodium may attain a more prominent role as a second line, maintenance therapy that can be employed after a sequence of ranibizumab and bevacizumab injections have been given (45). The rationale for this use is that it can preserve the beneficial physiological actions of some VEGF isoforms which may be needed over a long period of time while inhibiting the dominant VEGF $_{165}$ subtype and consequently reducing the chance of developing a new neovascular lesion. In addition, the current study was limited in that the case reports used as an index of the use of ranibizumab and bevacizumab may not be completely indicative of their use in ophthalmology clinics. These reports may only reflect current hypotheses and investigational uses that are still awaiting further clinical trials before they become more widely accepted in the future. Nonetheless, it may be some time before clinical trials are organized for many less common diseases prompting some clinicians who have not yet adopted the drug to begin introducing it at increasing amounts in the future.

The increasing off-label use of bevacizumab and ranibizumab beyond the numerous conditions identified here has the potential to also lead to an increasing number of adverse reactions to the drugs. VEGF has a number of critical roles in the vasculature including maintaining the health of the retinal pigment epithelium and the microcirculation,(46) and serving as a critical factor in the adaptive response to ischemic injury in which the elderly, who are often the population treated with these agents, are at greater risk. In response to ischemic injury, VEGF serves as a neuroprotectant directly by influencing antiapoptotic gene expression and indirectly by functioning as a vasodilator and increasing blood flow to the area (47). Its latter function is a result of its ability to alter the distribution of the tight junction protein occludin in endothelial cells $(48,49)$ and upregulate nitric oxide in arterioles and venules (50). Indeed, a recent study evaluating treatment of naïve patients with neovascular AMD noted significant retinal arteriolar narrowing after monthly intravitreal injections of ranibizumab (51). The 
concern for systemic effects, however, should be greater with bevacizumab than ranibizumab, since it can utilize endogenous immunoglobulin transport systems like the FcRn or neo-natal receptor, which are expressed at high levels in the eye and used to transport antibodies to help them escape catabolism (52). In fact, pharmacokinetic studies in rabbits have found persistent levels of bevacizumab in the serum that do not drop below $1 \mathrm{ug} / \mathrm{mL}$ until 30 days post-injection and nanogram levels in the contralateral eye after intravitreal injection of $1.25 \mathrm{mg}$ (53). Considering that normal serum VEGF levels are on the order of $100 \mathrm{pg} / \mathrm{mL}$ (54), an excess of free bevacizumab in the serum could neutralize the protective functions of VEGF and have clinical manifestations. Could we therefore see more systemic thromboembolic adverse events in the future as bevacizumab grows in importance? Even large clinical trials enrolling a few thousand patients may not have the statistical power yet to detect low rates of adverse events. One primary concern that is currently under investigation is whether long-term treatment with ranibizumab for wet AMD can accelerate a transition to geographic atrophy, a dry debilitating end-stage of AMD, since VEGF helps maintain the health of the normal retinal neurons and the retinal pigment epithelium. (55). Consequently, further large scale studies and effective mechanisms that allow for reporting of potential adverse events should be put in place to better identify relationships between intravitreal anti-VEGF therapy and adverse consequences.

\section{CONCLUSION}

Bevacizumab is a far-reaching anti-VEGF agent used in ophthalmology, being described for use in 58 different conditions. The smaller ranibizumab fragment is the only anti-VEGF currently approved for ocular use in neovascular AMD and has been described for use in 18 other eye diseases. As the use of bevacizumab and ranibizumab increases in our aging population, the potential for more adverse events with these agents will inevitably grow beyond the 20 published case reports of adverse events to date. Caution should be used by all treating physicians who opt to use these agents in their practice and patients should be fully informed regarding their use and be made aware of the off-label nature of these therapies.

\section{REFERENCES}

1. Kerbel R, Folkman J. Clinical translation of angiogenesis inhibitors. Nat Rev Cancer. 2002;2:727-39.

2. Hanahan D, Folkman J. Patterns and emerging mechanisms of the angiogenic switch during tumorigenesis. Cell. 1996;86:353-64.

3. Hurwitz H, Fehrenbacher L, Novotny W, Cartwright T, Hainsworth J, Heim W, et al. Bevacizumab plus irinotecan, fluorouracil, and leucovorin for metastatic colorectal cancer. N Engl J Med. 2004;350:2335-42.

4. Miller JW, Adamis AP, Shima DT, D'Amore PA, Moulton RS, O'Reilly MS, et al. Vascular endothelial growth factor/ vascular permeability factor is temporally and spatially correlated with ocular angiogenesis in a primate model. Am J Pathol. 1994;145:574-84.

5. Michels S, Rosenfeld PJ, Puliafito CA, Marcus EN, Venkatraman AS. Systemic bevacizumab (Avastin) therapy for neovascular age-related macular degeneration twelveweek results of an uncontrolled open-label clinical study. Ophthalmology. 2005;112:1035-47.

6. Rosenfeld PJ, Moshfeghi AA, Puliafito CA. Optical coherence tomography findings after an intravitreal injection of bevacizumab (avastin) for neovascular age-related macular degeneration. Ophthalmic Surg Lasers Imaging. 2005;36:331-5

7. Gragoudas ES, Adamis AP, Cunningham ET, Jr., Feinsod M, Guyer DR. Pegaptanib for neovascular age-related macular degeneration. N Engl J Med. 2004;351:2805-16.

8. Rosenfeld PJ, Brown DM, Heier JS, Boyer DS, Kaiser PK, Chung $\mathrm{CY}$, et al. Ranibizumab for neovascular age-related macular degeneration. N Engl J Med. 2006;355:1419-31.

9. Pascolini D, Mariotti SP, Pokharel GP, Pararajasegaram R, Etya'ale D, Negrel AD, et al. 2002 global update of available data on visual impairment: a compilation of population-based prevalence studies. Ophthalmic Epidemiol. 2004;11:67-115.

10. Congdon N, O'Colmain B, Klaver CC, Klein R, Munoz $B$, Friedman DS, et al. Causes and prevalence of visual impairment among adults in the United States. Arch Ophthalmol. 2004;122:477-85.

11. Friedman DS, O'Colmain BJ, Munoz B, Tomany SC, McCarty $C$, de Jong PT, et al. Prevalence of age-related macular degeneration in the United States. Arch Ophthalmol. 2004;122:564-72.

12. Sivaprasad S. Role of pegaptanib sodium in the treatment of neovascular age-related macular degeneration. Clin Ophthalmol. 2008;2:339-46.

13. Mordenti J, Cuthbertson RA, Ferrara N, Thomsen K, Berleau L, Licko V, et al. Comparisons of the intraocular tissue distribution, pharmacokinetics, and safety of 125I-labeled full-length and Fab antibodies in rhesus monkeys following 
intravitreal administration. Toxicol Pathol. 1999;27:536-44.

14. Klein RM, Klein RB. Avastin versus Lucentis: ethical issues in treatment of age-related macular degeneration. Retina. 2007;27:1163-5.

15. Ovid MEDLINE, Publication -Scope Notes, http://www.nlm. nih.gov/mesh/pubtypes2004.html.

16. Brown DM, Kaiser PK, Michels M, Soubrane G, Heier JS, Kim RY, et al. Ranibizumab versus verteporfin for neovascular age-related macular degeneration. $\mathrm{N}$ Engl J Med. 2006;355:1432-44.

17. Rosenfeld PJ, Brown DM, Heier JS, Boyer DS, Kaiser PK, Chung $\mathrm{CY}$, et al. Ranibizumab for neovascular age-related macular degeneration. New Engl J Med. 2006;355:1419-31.

18. Heier JS, Boyer DS, Ciulla TA, Ferrone PJ, Jumper JM, Gentile RC, et al. Ranibizumab combined with verteporfin photodynamic therapy in neovascular age-related macular degeneration: year 1 results of the FOCUS Study. Arch Ophthalmol. 2006;124:1532-42.

19. Regillo $C D$, Brown $D M$, Abraham $P$, Yue $H$, lanchulev $\mathrm{T}$, Schneider $\mathrm{S}$, et al. Randomized, double-masked, sham-controlled trial of ranibizumab for neovascular agerelated macular degeneration: PIER Study year 1. Am J Ophthalmol. 2008;145:239-48.

20. Arias L, Caminal JM, Rubio M, Pujol O, Arruga J. Retinal pigment epithelial tears after intravitreal bevacizumab injection for predominantly classic choroidal neovascularization. Eur J Ophthalmol. 2007;17:992-5.

21. Aggio FB, Farah ME, de Melo GB, d'Azevedo PA, Pignatari AC, Hofling-Lima AL, et al. Acute endophthalmitis following intravitreal bevacizumab (Avastin) injection. Eye. 2007;21:408-9.

22. Kim KS, Chang HR, Song S, Kim KS, Chang HR, Song S. Ischaemic change after intravitreal bevacizumab (Avastin) injection for macular oedema secondary to non-ischaemic central retinal vein occlusion. Acta Opthalmol. 2008;86:9257.

23. Chung EJ, Koh HJ, Chung EJ, Koh HJ. Retinal detachment with macular hole following combined photodynamic therapy and intravitreal bevacizumab injection. Kor J Ophthalmol. 2007;21:185-7.

24. Yokoyama K, Choshi T, Kimoto K, Shinoda K, Nakatsuka K, Yokoyama K, et al. Retinal circulatory disturbances following intracameral injection of bevacizumab for neovascular glaucoma. Acta Opthalmol. 2008;86:927-8.

25. Tranos P, Gemenetzi M, Papandroudis A, Chrisafis C, Papadakos D. Progression of diabetic tractional retinal detachment following single injection of intravitreal Avastin. Eye. 2008;22:862.
26. Khalili MR, Mehdizadeh M, Mehryar M, Khalili MR, Mehdizadeh M, Mehryar M. Herpetic epithelial keratitis after intravitreal injection of bevacizumab (avastin). Cornea. 2009;28:360-1.

27. Amselem L, Diaz-Llopis M, Garcia-Delpech S, Montero J, Palomares P, Cervera E, et al. Papulopustular eruption after intravitreal bevacizumab (Avastin). Acta Opthalmol. 2009;87:110-1.

28. Matsumoto $\mathrm{Y}$, Freund KB, Peiretti E, Cooney MJ, Ferrara DC, Yannuzzi LA, et al. Rebound macular edema following bevacizumab (Avastin) therapy for retinal venous occlusive disease. Retina. 2007;27:426-31.

29. Park HJ, Guy J, Park H-J, Guy J. Sixth nerve palsy post intravitreal bevacizumab for AMD: a new possibly causal relationship and complication? Binocular Vision \& Strabismus Quarterly. 2007;22:209.

30. Jalil A, Fenerty $C$, Charles $S$. Intravitreal bevacizumab (Avastin) causing acute glaucoma: an unreported complication. Eye. 2007;21:1541.

31. Kahook MY, Kimura AE, Wong LJ, Ammar DA, Maycotte $\mathrm{MA}$, Mandava $\mathrm{N}$, et al. Sustained elevation in intraocular pressure associated with intravitreal bevacizumab injections. Ophthalmic Surg Lasers Imaging. 2009;40:2935.

32. Meyer $\mathrm{CH}$, Mennel S, Horle S, Schmidt JC, Meyer $\mathrm{CH}$, Mennel $S$, et al. Visual hallucinations after intravitreal injection of bevacizumab in vascular age-related macular degeneration. Am J Ophthalmol. 2007;143:169-70.

33. Sisk RA, Davis JL, Dubovy SR, Smiddy WE, Sisk RA, Davis $\mathrm{JL}$, et al. Sympathetic ophthalmia following vitrectomy for endophthalmitis after intravitreal bevacizumab. Ocul Immunol Inflamm.2008;16:236-8.

34. Pieramici DJ, Avery RL, Castellarin AA, Nasir MA, Rabena $M$, Pieramici DJ, et al. Case of anterior uveitis after intravitreal injection of bevacizumab. Retina. 2006;26:8412.

35. Chen E, Hsu J, Park CH, Chen E, Hsu J, Park CH. Acute visual acuity loss following intravitreal bevacizumab for diabetic macular edema. Ophthalmic Surg Lasers Imaging. 2009;40:68-70.

36. Chieh JJ, Fekrat S, Chieh JJ, Fekrat S. Large subretinal hemorrhage after intravitreal bevacizumab (Avastin) for age-related macular degeneration. Ann Ophthalmol. 2007;39:51-2.

37. Hosseini H, Razeghinejad MR, Hosseini H, Razeghinejad MR. Anterior ischemic optic neuropathy after intravitreal injection of bevacizumab. J Neurophthalmol. 2009;29:1601. 
38. Neri P, Mariotti C, Mercanti L, Salvolini S, Giovannini A, Neri $P$, et al. Vitritis in the contralateral uninjected eye following intravitreal bevacizumab (Avastin). Int Ophthalmol. 2008;28:425-7

39. Apte RS, Apte RS. Retinal pigment epithelial tear after intravitreal ranibizumab for subfoveal CNV secondary to AMD. Int Ophthalmol. 2007;27:59-61.

40. Bakri SJ, McCannel CA, Edwards AO, Moshfeghi DM, Bakri SJ, McCannel CA, et al. Persisent ocular hypertension following intravitreal ranibizumab. Graefe Arch Clin Exp Ophthalmol. 2008;246:955-8.

41. Mitra RA, Pollack JS. Preferences and Trends Mini-Survey: Avastin Usage. Chico, CA: American Society of Retinal Specialists; 2006.

42. Arevalo JF, Garcia-Amaris RA. Intravitreal bevacizumab for diabetic retinopathy. Curr Diabetes Rev. 2009;5:39-46.

43. Moraczewski AL, Lee RK, Palmberg PF, Rosenfeld $\mathrm{PJ}$, Feuer WJ. Outcomes of treatment of neovascular glaucoma with intravitreal bevacizumab. $\mathrm{Br} \mathrm{J}$ Ophthalmol. 2009;93:589-93.

44. Micieli JA, Surkont M, Smith AF. A Systematic Analysis of the Off-Label Use of Bevacizumab for Severe Retinopathy of Prematurity. Am J Ophthalmol. 2009;148:536-43.

45. Hughes MS, Sang DN. Safety and efficacy of intravitreal bevacizumab followed by pegaptanib maintenance as a treatment regimen for age-related macular degeneration. Ophthalmic Surg Lasers Imaging. 2006;37:446-54.

46. Baffert F, Le T, Sennino B, Thurston G, Kuo CJ, Hu-Lowe $D$, et al. Cellular changes in normal blood capillaries undergoing regression after inhibition of VEGF signaling. Am J Physiol Heart Circ Physiol. 2006;290:H547-59.

47. Nishijima K, Ng YS, Zhong L, Bradley J, Schubert W, Jo $\mathrm{N}$, et al. Vascular endothelial growth factor-A is a survival factor for retinal neurons and a critical neuroprotectant during the adaptive response to ischemic injury. Am J Pathol. 2007;171:53-67.

48. Antonetti DA, Barber AJ, Hollinger LA, Wolpert EB, Gardner TW. Vascular endothelial growth factor induces rapid phosphorylation of tight junction proteins occludin and zonula occluden 1. A potential mechanism for vascular permeability in diabetic retinopathy and tumors. J Biol Chem. 1999;274:23463-7.

49. Harhaj NS, Felinski EA, Wolpert EB, Sundstrom JM, Gardner TW, Antonetti DA. VEGF activation of protein kinase C stimulates occludin phosphorylation and contributes to endothelial permeability. Investigative Ophthalmology \& Visual Science. 2006;47:5106-15.

50. Wu HM, Huang Q, Yuan Y, Granger HJ. VEGF induces NOdependent hyperpermeability in coronary venules. Am J Physiol. 1996;271:H2735-9.

51. Papadopoulou DN, Mendrinos E, Mangioris G, Donati G, Pournaras CJ. Intravitreal Ranibizumab May Induce Retinal Arteriolar Vasoconstriction in Patients with Neovascular Age-related Macular Degeneration. Ophthalmology. 2009;116:1755-61

52. Kim H, Fariss RN, Zhang C, Robinson SB, Thill M, Csaky KG. Mapping of the neonatal Fc receptor in the rodent eye. Invest Ophthalmol VisSci.2008;49:2025-9.

53. Bakri SJ, Snyder MR, Reid JM, Pulido JS, Ezzat MK, Singh RJ. Pharmacokinetics of intravitreal ranibizumab (Lucentis). Ophthalmology. 2007;114:2179-82.

54. Kimura K, Hashiguchi T, Deguchi T, Horinouchi S, Uto $\mathrm{T}$, Oku $\mathrm{H}$, et al. Serum VEGF--as a prognostic factor of atherosclerosis. Atherosclerosis. 2007;194:182-8.

55. Csaky K, Do DV. Safety implications of vascular endothelial growth factor blockade for subjects receiving intravitreal anti-vascular endothelial growth factor therapies. Am J Ophthalmol. 2009;148:647-56.

Jonathan Micieli, MDCM (2012) is a medical student at McGill University and has receieved a B Sc. (Hons) from the University of Toronto in Laboratory Medicine and Pathobiology. He has had the opportunity to work on various projects regarding anti-angiogenic therapy for "wet" age-related macular degeneration and retinopathy of prematurity and has published on the topic in a number of peer-reviewed journals including the American Journal of Ophthalmology.

Andrew Micieli is an undergraduate student at the University of Toronto where he is studying Life Sciences. He has been involved in a number of research projects during his time in university including those that have evaluated the use of anti-angiogenic drugs in ophthalmology and other topics in this field. 